\title{
Improved Noise and Device Performances of AlGaN/GaN HEMTs with In Situ Silicon Carbon Nitride (SiCN) Cap Layer
}

\author{
Yeo-Jin Choi ${ }^{1}$, Jae-Hoon Lee ${ }^{2}$, Jin-Seok Choi ${ }^{1}$, Sung-Jin An ${ }^{1}$, Young-Min Hwang ${ }^{3}$, Jae-Seung Roh ${ }^{1}$ \\ and Ki-Sik $\operatorname{Im}^{3, *}$ \\ 1 Department of Advanced Materials Science and Engineering, Kumoh National Institute of Technology, \\ Gumi 39177, Korea; dota23@kumoh.ac.kr (Y.-J.C.); jschoi@kumoh.ac.kr (J.-S.C.); \\ sungjinan@kumoh.ac.kr (S.-J.A.); jsroh@kumoh.ac.kr (J.-S.R.) \\ 2 Yield Enhancement Team, Foundry, Samsung Electronics Company Ltd., Yongin 17113, Korea; \\ jaehoon03.lee@samsung.com \\ 3 Advanced Material Research Center, Kumoh National Institute of Technology, Gumi 39177, Korea; \\ hdhym@kumoh.ac.kr \\ * Correspondence: ksim@kumoh.ac.kr
}

check for

updates

Citation: Choi, Y.-J.; Lee, J.-H.; Choi, J.-S.; An, S.-J.; Hwang, Y.-M.; Roh, J.-S.; Im, K.-S. Improved Noise and Device Performances of AlGaN/GaN HEMTs with In Situ Silicon Carbon Nitride (SiCN) Cap Layer. Crystals 2021, 11, 489. https://doi.org/ $10.3390 /$ cryst11050489

Academic Editor: Dmitri Donetski

Received: 8 April 2021

Accepted: 25 April 2021

Published: 27 April 2021

Publisher's Note: MDPI stays neutral with regard to jurisdictional claims in published maps and institutional affiliations.

Copyright: (C) 2021 by the authors Licensee MDPI, Basel, Switzerland. This article is an open access article distributed under the terms and conditions of the Creative Commons Attribution (CC BY) license (https:// creativecommons.org/licenses/by/ $4.0 /)$.

\begin{abstract}
We investigated the effects of in situ silicon carbon nitride ( $\mathrm{SiCN}$ ) cap layer of AlGaN/GaN high-electron mobility transistors (HEMTs) on DC, capacitance-voltage (C-V) and low-frequency noise (LFN). The proposed device with $\mathrm{SiCN}$ cap layer exhibited enhanced drain current, reduced gate leakage current, low interface trap density $\left(D_{i t}\right)$, and high on/off ratio thanks to the passivation effect, compared to the device without $\mathrm{SiCN}$ cap layer. Both devices clearly showed $1 / \mathrm{f}$ noise behavior with carrier number fluctuations $(\mathrm{CNF})$, regardless of the existence of SiCN cap layer. The proposed device presented the relative low trap density $\left(\mathrm{N}_{\mathrm{it}}\right)$ and reduced access noise due to the effective surface passivation in source-drain access region compared to the device without SiCN cap layer. From the improved DC, C-V and noise results of the proposed device, the in situ SiCN cap layer plays an important role in the passivation layer and gate oxide layer in AlGaN/GaN HEMT.
\end{abstract}

Keywords: AlGaN/GaN; HEMTs; cap layer; low-frequency noise; carrier number fluctuations

\section{Introduction}

Owing to superior GaN material properties such as wide band gap ( $3.4 \mathrm{eV})$, high electron saturation velocity $\left(2.5 \times 10^{7} \mathrm{~cm} / \mathrm{s}\right)$, and large breakdown electric field $(3.3 \mathrm{MV} / \mathrm{cm})$, $\mathrm{AlGaN} / \mathrm{GaN}$ high-electron mobility transistors (HEMTs) have many advantages for highpower and high-frequency device applications [1]. In addition, the donor-like surface states on top of AlGaN/GaN HEMTs induce large sheet electron concentrations $\left(\mathrm{n}_{\mathrm{s}}\right)$ at the AlGaN/GaN heterointerface and are also separated from the channel, which leads to a high electron mobility $\left(\mu_{\mathrm{e}}\right)$ of two-dimensional electron gas (2-DEG) [2,3]. However, the donor-like surface states occasionally make high leakage current and severe current collapse when operating under high power and frequency conditions, which impacts on the device performance and reliability [4].

In order to solve this issue, the deposition of several dielectric materials such as in situ or ex situ $\mathrm{SiN}_{x}, \mathrm{GaN}, \mathrm{SiO}_{2}$, and $\mathrm{Al}_{2} \mathrm{O}_{3}$, has been reported, which play the role of a gate insulator and/or surface passivation layer in AlGaN/GaN HEMTs [5,6]. Unfortunately, the ex situ dielectric deposition can inevitably generate additional growth- and processrelayed defects on the devices. In contrast, the in situ growth method has many benefits in reducing the threading dislocation density, suppressing surface roughness, and mitigating the modification of the interface property, because an in situ dielectric layer is directly grown on the AlGaN barrier layer in metal-organic chemical vapor deposition (MOCVD) chamber without plasma damage or ambient exposure during deposition [6,7].

Lee et al. [7] reported improved device performance by utilizing an in situ silicon carbon nitride ( $\mathrm{SiCN}$ ) cap layer, due to the enhanced surface passivation effect. Surface 
passivation also affects reduced noise performance in AlGaN/GaN-based or InAlN/GaNbased HEMTs [8-10]. No enhancement of noise performance according to the increased in fsitu SiN thickness was reported by Rzin et al. [11]. However, there is no report on the effect of the gate dielectric on noise performance of AlGaN/GaN HEMTs with in situ SiCN cap layer.

In this work, we fabricate, characterize, and compare the AlGaN/GaN HEMTs with and without $\mathrm{SiCN}$ cap layer by considering high resolution X-ray diffraction (HRXRD), Hall effects, transmission electron microscopy (TEM), DC, capacitance-voltage (C-V), and low-frequency noise (LFN). These characteristics provide information on the effects of the $\mathrm{SiCN}$ cap layer on the device and the LFN performance of the fabricated devices.

\section{Epitaxy Growth and Device Fabrication}

The proposed $\mathrm{AlGaN} / \mathrm{GaN}$ heterostructure with in situ $\mathrm{SiCN}$ cap layer was grown on a 4-inch sapphire substrate using MOCVD (AIXTRON, Herzogenrath, Germany). Trimethylaluminum (TMAl), trimethylgallium (TMGa), ammonia $\left(\mathrm{NH}_{3}\right)$, di-tertiary-butyl-silane (DTBSi), and carbon tetrabromide $\left(\mathrm{CBr}_{4}\right)$ were employed as gas sources of $\mathrm{Al}, \mathrm{Ga}, \mathrm{N}, \mathrm{Si}$, and $\mathrm{C}$, respectively. The epitaxial layer structure consists of a $30 \mathrm{~nm}$-thick initial nucleation $\mathrm{GaN}$ layer at low temperature of $950^{\circ} \mathrm{C}$, a $3 \mu \mathrm{m}$-thick highly-resistive $\mathrm{GaN}$ buffer layer at $1050^{\circ} \mathrm{C}$, and a $20 \mathrm{~nm}$-thick $\mathrm{AlGaN}$ barrier layer, while maintaining the gas pressure at 300 Torr. A $7 \mathrm{~nm}$-thick SiCN cap layer grown at $1100{ }^{\circ} \mathrm{C}$ during $60 \mathrm{~min}$ was finally deposited to finish the epitaxial growth. The detailed structural characterizations of the in situ SiCN cap layer were reported in previous work [7]. Two different types of epitaxial layer were prepared to fabricate the AlGaN/GaN HEMTs (1), with and (2) without SiCN cap layer (Figure 1a,b).

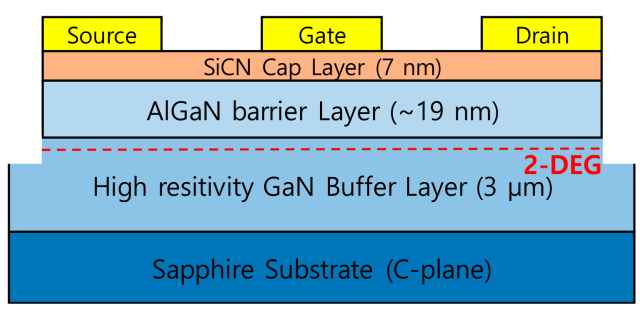

(a)

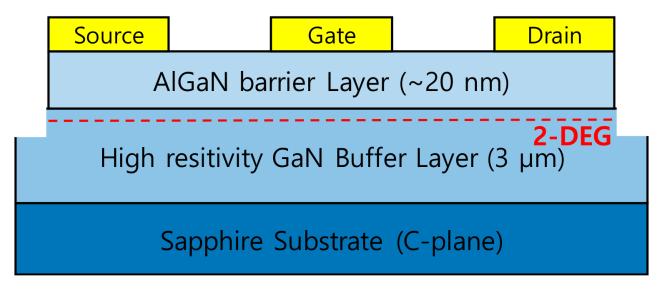

(b)

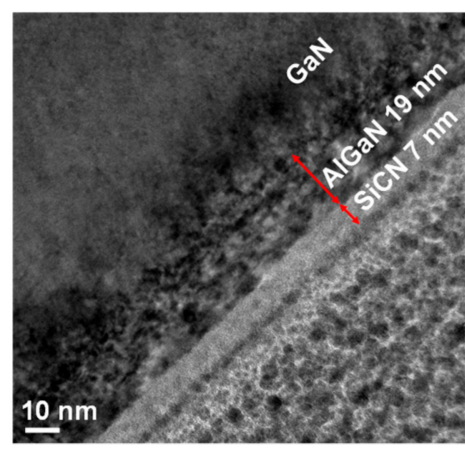

(c)

Figure 1. Schematic illustrations of the fabricated AlGaN/GaN HEMTs (a) with and (b) without in situ SiCN cap layer. No ex situ passivation. (c) Cross-sectional TEM image of SiCN/AlGaN/GaN structure with layer thickness.

The reference sample grown without $\mathrm{SiCN}$ cap layer exhibited a $\mathrm{n}_{\mathrm{s}}$ of $2.7 \times 10^{12} \mathrm{~cm}^{-2}$ and $\mu_{\mathrm{e}}$ of $1200 \mathrm{~cm}^{2} / \mathrm{V} \cdot \mathrm{s}$ measured by Hall effect, which leads to poor sheet resistance $\left(\mathrm{R}_{\mathrm{sh}}\right)$ of $1923 \Omega / \mathrm{sq}$. The degraded $\mathrm{R}_{\mathrm{sh}}$ is due to the relatively low $\mathrm{Al}$ composition of $12 \%$ in the AlGaN barrier layer, which was confirmed by high resolution X-ray diffraction (HRXRD). On the other hand, the proposed sample with $\mathrm{SiCN}$ cap layers showed increased $\mathrm{n}_{\mathrm{s}}$ of $3.7 \times 10^{12} \mathrm{~cm}^{-2}$ and $\mu_{\mathrm{e}}$ of $1690 \mathrm{~cm}^{2} / \mathrm{V} \cdot \mathrm{s}$ caused by the positive charge incorporation of the AlGaN surface during the growth of SiCN cap layer [7]. From HRXRD measurement, both samples presented almost the same $\mathrm{Al}$ composition and crystal quality of the GaN buffer, layer excepting a slight difference of AlGaN barrier thickness. Both samples achieved a smooth morphology, but the root mean square (RMS) roughness of $1.37 \mathrm{~nm}$ for the proposed sample is lower than that of the reference sample $(1.44 \mathrm{~nm})$ analyzed by atomic force microscopy (AFM). The detailed electrical properties for the two samples are shown in Table 1. The TEM image in Figure 1c showed that the $7 \mathrm{~nm}$-thick SiCN cap layer is successfully deposited on the $19 \mathrm{~nm}$-thick AlGaN barrier layer, whose values are similar to that of the HRXRD result in Table 1. 
Table 1. Structural properties and sheet resistances in AlGaN/GaN HEMTs with and without SiCN cap layer measured by Hall effect, HRXRD, and AFM.

\begin{tabular}{|c|c|c|c|c|c|c|}
\hline \multirow{2}{*}{$\begin{array}{c}\text { Samples } \\
\text { SiCN Cap } \\
\text { Layer }\end{array}$} & \multicolumn{3}{|c|}{ Hall Effect } & \multicolumn{2}{|c|}{ HRXRD } & \multirow{2}{*}{$\begin{array}{c}\text { AFM }\left(5 \times 5 \mu \mathrm{m}^{2}\right) \\
\begin{array}{c}\text { RMS } \\
(\mathrm{nm})\end{array}\end{array}$} \\
\hline & $\begin{array}{c}R_{\text {sh }} \\
(\Omega / \text { sq. })\end{array}$ & $\begin{array}{c}\mu_{\mathrm{e}} \\
\left(\mathrm{cm}^{2} / \mathrm{V} \cdot \mathrm{s}\right)\end{array}$ & $\begin{array}{c}\mathrm{n}_{\mathrm{s}} \\
\left(10^{12} \mathrm{~cm}^{-2}\right)\end{array}$ & $\begin{array}{c}\text { Al Composition } \\
(\%)\end{array}$ & $\begin{array}{c}\text { AlGaN Thickness } \\
\text { (nm) }\end{array}$ & \\
\hline $0 \mathrm{~nm}$ & 1923 & 1200 & 2.7 & 12 & 20.5 & 1.44 \\
\hline $7 \mathrm{~nm}$ & 1018 & 1690 & 3.7 & 12.8 & 19.5 & 1.37 \\
\hline
\end{tabular}

\section{Results and Discussion}

Figure 2 shows the normalized drain current $\left(\mathrm{I}_{\mathrm{ds}}\right)$ and gate leakage current as a function of the gate voltage $\left(\mathrm{V}_{\mathrm{gs}}\right)$. The drain current for the fabricated AlGaN/GaN HEMTs with $\mathrm{SiCN}$ cap layer exhibits the negative shift of threshold voltage $\left(\mathrm{V}_{\text {th }}\right)$ of approximately $0.7 \mathrm{~V}$ compared to the reference device. The reason for the $V_{\text {th }}$ shift is because of the enhancement of the 2-DEG density and increased gate oxide thickness. The off-state and gate leakage current for the $\mathrm{SiCN}$ capped device exhibit much lower values compared to the reference device, which leads the device to have a high on/off ratio. This is reflected in the fact that the $\mathrm{SiCN}$ cap layer effectively passivates the AlGaN surface, which results in reducing the gate leakage current.

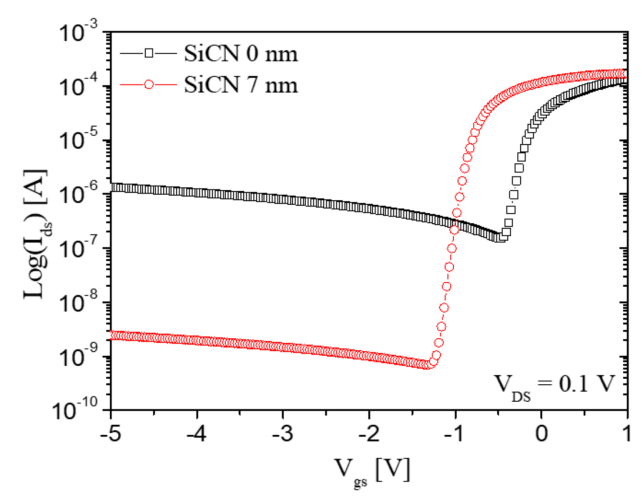

(a)

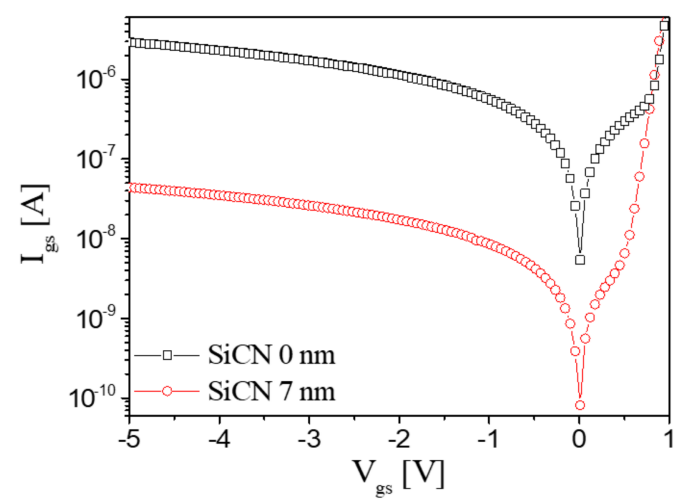

(b)

Figure 2. (a) Normalized drain currents (logarithmic scale) at $\mathrm{V}_{\mathrm{ds}}=0.1 \mathrm{~V}$ and (b) normalized gate leakage currents versus gate voltage of $\mathrm{AlGaN} / \mathrm{GaN}$ HEMTs with and without the $\mathrm{SiCN}$ cap layer $\left(\mathrm{W}_{\mathrm{g}}=50 \mu \mathrm{m}\right)$.

Frequency-dependent $\mathrm{C}-\mathrm{V}$ measurements are performed at $10 \mathrm{kHz} 1 \mathrm{MHz}$ using the circular-type metal-insulator-semiconductor (MIS) capacitor fabricated on the same wafer of both devices, as shown in Figure 3. Both capacitors exhibit almost the same frequency dispersion, whereas the device without $\mathrm{SiCN}$ cap layer in Figure 3a shows a severe pinchoff voltage shift $\left(\Delta \mathrm{V}_{\text {shift }}\right)$ according to the increased frequency compared to that with $\mathrm{SiCN}$ cap layer (Figure $3 b$ ). The effective trap states density $\left(D_{i t}\right)$ is calculated using the equation for $D_{i t}=C_{m} \times \Delta V_{\text {shift }} / q$, where $C_{m}$ is the measured capacitance and $q$ is the electron charge. The positive voltage shift $\left(\Delta \mathrm{V}_{\text {shift }}\right)$ obtained from $10 \mathrm{kHz}$ to $1 \mathrm{MHz}$ are $0.23 \mathrm{~V}$ and $0.13 \mathrm{~V}$ for the device without and with $\mathrm{SiCN}$ cap layer, respectively, corresponding to $\mathrm{D}_{\text {it }}$ of $5.7 \times 10^{11} \mathrm{~cm}^{-2} \cdot \mathrm{eV}^{-1}$ and $3.2 \times 10^{11} \mathrm{~cm}^{-2} \cdot \mathrm{eV}^{-1}$. This demonstrates that the SiCN cap layer effectively reduces the trap density on the AlGaN barrier layer. It is also interesting that the maximum gate voltage can be applied to $1.2 \mathrm{~V}$ for the device with $\mathrm{SiCN}$ cap layer in Figure $3 \mathrm{~b}$ without any degradation of capacitance, thanks to the good insulator property of the $\mathrm{SiCN}$ cap layer. 


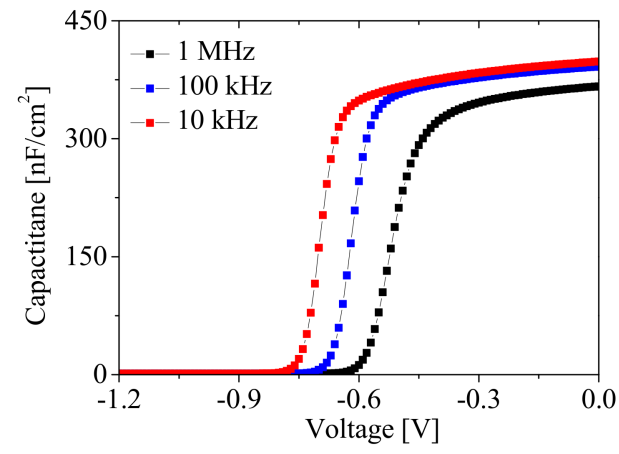

(a)

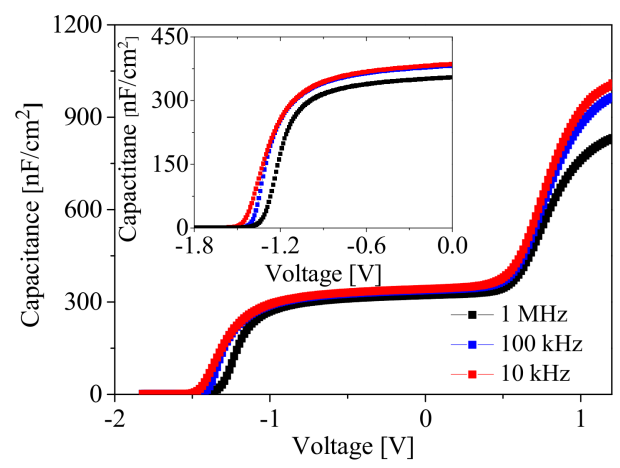

(b)

Figure 3. Capacitance versus gate voltage of AlGaN/GaN HEMTs (a) without and (b) with the SiCN cap layer measured at frequency from $10 \mathrm{kHz}$. $\mathrm{kHz}$ to $1 \mathrm{MHz}$. The inset indicates to the enlargement of the first hump in C-V curves of $(\mathbf{b})$.

To investigate the effect of the SiCN cap layer on the noise performance, LFNs were performed using a noise measurement system from Synergie Concept with shielding box [12]. LFN measurement is an effective diagnostic method to find interface and/or oxide traps as well as surface traps, because the noise at the AlGaN/GaN heterointerface is originated by oxide trapping/de-trapping of electrons in the 2-DEG channel. This conduction mechanism obtained by LFN is interpreted using the carrier number fluctuations (CNF) model proposed by McWhorter [13].

Noise spectra with frequency $(f)$ ranges from $4 \mathrm{~Hz}$ to $10^{3} \mathrm{~Hz}$ are reported in Figure 4a. Both devices exhibited clearly $1 / f$ noise properties. When applying the $\left(\mathrm{V}_{\mathrm{gs}}-\mathrm{V}_{\mathrm{th}}\right)$ of $0.4 \mathrm{~V}$ in the linear region of drain voltage $\left(\mathrm{V}_{\mathrm{ds}}\right)=0.1 \mathrm{~V}$, the noise power spectral densities $\left(\mathrm{S}_{\mathrm{Id}}\right)$ for the device without the $\mathrm{SiCN}$ cap layer are lower than those of the device with the $\mathrm{SiCN}$ cap layer in spite of its high gate leakage current. This result is totally different to the previous work, reported by Hasan, et al. [10]. However, the measured noises between HEMT and MIS-HEMTs with $\mathrm{SiO}_{2}$ were compared at the same gate voltage $\left(\mathrm{V}_{\mathrm{gs}}=0 \mathrm{~V}\right)$, not the same gate overdrive voltage, $\left(\mathrm{V}_{\mathrm{gs}}-\mathrm{V}_{\mathrm{th}}\right)$ [10].

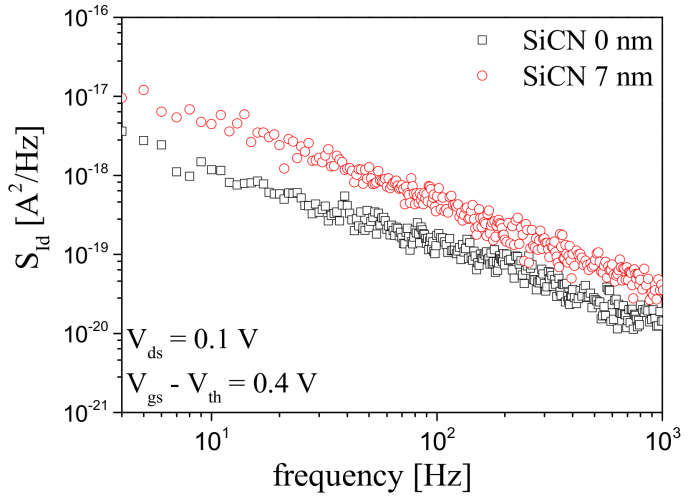

(a)

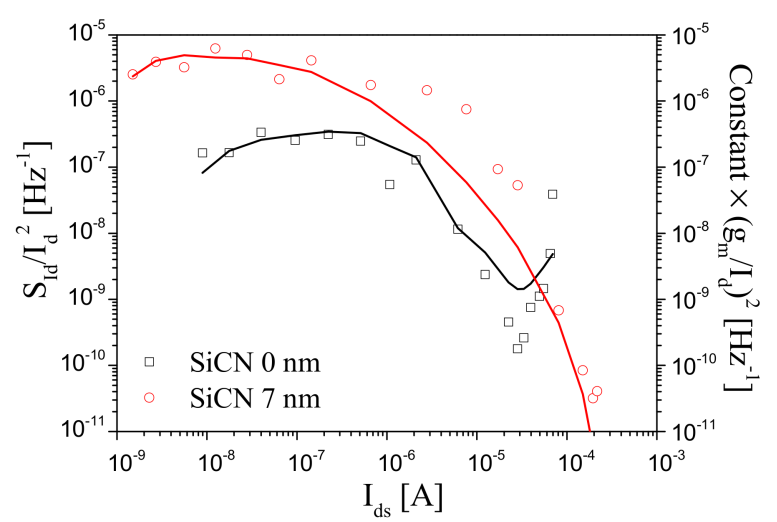

(b)

Figure 4. (a) $\mathrm{S}_{\mathrm{Id}}$ versus frequency at the gate overdrive voltage $\left(\mathrm{V}_{\mathrm{gs}}-\mathrm{V}_{\mathrm{th}}\right)=0.4 \mathrm{~V}$, (b) $\mathrm{S}_{\mathrm{Id}} / \mathrm{I}_{\mathrm{ds}}{ }^{2}$ (left scale, scatter symbols) and (constant $\left.\times\left(\mathrm{g}_{\mathrm{m}} / \mathrm{I}_{\mathrm{ds}}\right)^{2}\right)$ (right scale, solid lines) according to drain current in the device without (black square) and with (red circle) $\mathrm{SiCN}$ cap layer, respectively $\left(\mathrm{V}_{\mathrm{ds}}=0.1 \mathrm{~V}\right)$.

To present the comparison of noise levels more clearly for both devices, the normalized noise power spectral densities $\left(\mathrm{S}_{\mathrm{Id}} / \mathrm{I}_{\mathrm{ds}}{ }^{2}\right)$ according to the $\mathrm{I}_{\mathrm{ds}}$ (sweeping from subthreshold to strong accumulation region) at $\mathrm{f}=10 \mathrm{~Hz}$ are shown in Figure $4 \mathrm{~b}$. Overall $\mathrm{S}_{\mathrm{Id}} / \mathrm{I}_{\mathrm{ds}}{ }^{2}$ for the device with $\mathrm{SiCN}$ cap layer were higher values than those for the device, except for the increased $\mathrm{S}_{\mathrm{Id}} / \mathrm{I}_{\mathrm{ds}}{ }^{2}$ at high drain current caused by large access resistance [14]. 
If $\mathrm{S}_{\mathrm{Id}} / \mathrm{I}_{\mathrm{ds}}{ }^{2}$ follows $\left(\mathrm{g}_{\mathrm{m}} / \mathrm{I}_{\mathrm{ds}}\right)^{2}$ in Figure $4 \mathrm{~b}$, this clearly indicates that both devices exhibit the dominance of CNF noise mechanism and can be extracted to the trap density using Equation (1) [15,16],

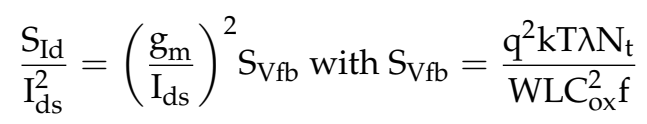

where $S_{\mathrm{Vfb}}$ is the flat band voltage fluctuation, $\mathrm{q}$ is the electron charge, $\mathrm{kT}$ is the thermal energy, $\lambda$ is the oxide tunneling attenuation distance $(\lambda=0.11 \mathrm{~nm}[14]), \mathrm{N}_{\mathrm{t}}$ is the volumetric oxide trap density, WL is the channel area, and $\mathrm{C}_{\mathrm{ox}}$ is the gate dielectric capacitance per unit area. The obtained $S_{\mathrm{Vfb}}$ for both devices were the same at $5.0 \times 10^{-10} \mathrm{~V}^{2} \cdot \mathrm{Hz}^{-1}$. The corresponding $\mathrm{N}_{\mathrm{t}}$ were calculated at $2.7 \times 10^{20} \mathrm{~cm}^{-3} \cdot \mathrm{eV}^{-1}$ for the device without $\mathrm{SiCN}$ layer and $2.5 \times 10^{20} \mathrm{~cm}^{-3} \cdot \mathrm{eV}^{-1}$ for the device with $\mathrm{SiCN}$ layer, respectively, considering the measured maximum $\mathrm{C}_{\mathrm{ox}}$ value of $398 \mathrm{nF} / \mathrm{cm}^{2}$ and $385 \mathrm{nF} / \mathrm{cm}^{2}$ from the $\mathrm{C}-\mathrm{V}$ curves at $\mathrm{f}=10 \mathrm{kHz}$ and $\mathrm{V}_{\mathrm{gs}}=0 \mathrm{~V}$ in Figure 3. The reason for the low $\mathrm{N}_{\mathrm{t}}$ for the device with SiCN cap layer is because the in situ $\mathrm{SiCN}$ cap layer mitigates trap density in the AlGaN barrier layer and plays an important role as the gate oxide layer. This phenomenon is coincident with the decreased $D_{i t}$ obtained from the $\mathrm{C}-\mathrm{V}$ result of the device with $\mathrm{SiCN}$ cap layer, as shown in Figure 3.

The $\left(\mathrm{S}_{\mathrm{Id}} / \mathrm{I}_{\mathrm{ds}}{ }^{2}\right)$ for the device without $\mathrm{SiCN}$ cap layer is rapidly proportional to $\mathrm{I}_{\mathrm{ds}}{ }^{2}$ at high drain current of $\sim 10^{4} \mathrm{~A}$, which means that the source-drain resistance fluctuations model is involved, using the following Equation (2) [17],

$$
\frac{\mathrm{S}_{\mathrm{Id}}}{\mathrm{I}_{\mathrm{ds}}^{2}}=\left(\frac{\mathrm{g}_{\mathrm{m}}}{\mathrm{I}_{\mathrm{ds}}}\right)^{2} \mathrm{~S}_{\mathrm{Vfb}}+\mathrm{S}_{\mathrm{R}_{\mathrm{sd}}}\left(\frac{\mathrm{I}_{\mathrm{ds}}}{\mathrm{V}_{\mathrm{ds}}}\right)^{2}
$$

where $S_{\text {Rsd }}$ is the spectral density of source-drain series resistance $\left(S_{R s d}=10^{-2} \Omega^{2} \cdot \mathrm{Hz}^{-1}\right)$. The reason for the series resistance of the device without $\mathrm{SiCN}$ cap layer is due to the poor $R_{\mathrm{sh}}$ from Hall measurement (Table 1 ) and the relatively high gate leakage current (Figure $2 \mathrm{~b}$ ). On the other hand, the device with the $\mathrm{SiCN}$ cap layer has relatively low access resistance without source-drain resistance fluctuations, which indicates that the $\mathrm{SiCN}$ cap layer effectively passivates the AlGaN surface of the fabricated device.

The $\mathrm{S}_{\mathrm{Id}} / \mathrm{I}_{\mathrm{ds}}{ }^{2}$ according to the $\left(\mathrm{V}_{\mathrm{gs}}-\mathrm{V}_{\mathrm{th}}\right)$ is displayed in Figure 5 . Without SiCN cap layer shows a dependence of $\sim\left(1 / \mathrm{V}_{\mathrm{gs}}\right)^{2}$, except for the large access resistance region at a high drain current of $10^{-4} \sim 10^{-5} \mathrm{~A}$. This reflects that the main noise source in AlGaN/GaN HEMT without $\mathrm{SiCN}$ cap layer is mainly due to channel noise [10], which means that the device has a large access noise. On the other hand, the device with $\mathrm{SiCN}$ cap layer showed a large negative slope of $\left(1 / \mathrm{V}_{\mathrm{gs}}\right)$, which elucidates that the channel noise is slightly smaller than or comparable to the access noise, due to the effective passivation effect of the $\mathrm{SiCN}$ cap layer in the access region.

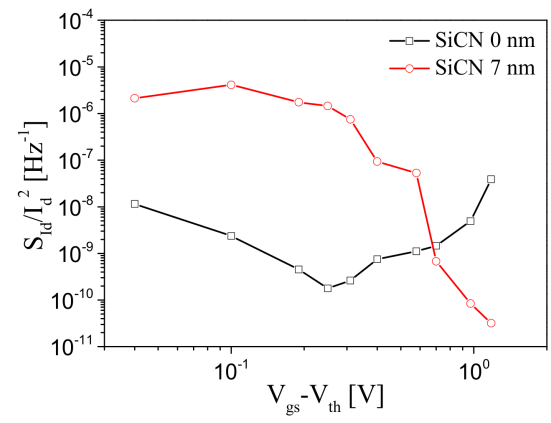

Figure 5. $\left(\mathrm{S}_{\mathrm{Id}} / \mathrm{I}_{\mathrm{ds}}\right)^{2}$ as a function of $\left(\mathrm{V}_{\mathrm{gs}}-\mathrm{V}_{\mathrm{th}}\right)$ in the device without (black square) and with (red circle) $\mathrm{SiCN}$ cap layer, respectively $\left(\mathrm{V}_{\mathrm{ds}}=0.1 \mathrm{~V}\right)$. 


\section{Conclusions}

Improved electrical characteristics of the AlGaN/GaN HEMT with in situ SiCN cap layer were observed because the $\mathrm{SiCN}$ cap layer effectively passivates the surface of the device. Using C-V and LFN characteristics, the trap density and source-drain resistance fluctuations were estimated, indicating that the proposed device exhibited reduced trap density and small access noise compared to the reference device without $\mathrm{SiCN}$ cap layer. Based on the noise results, the in situ $\mathrm{SiCN}$ cap layer is preferred in adopting the passivation layer as well as the gate oxide layer in AlGaN/GaN HEMT.

Author Contributions: Writing-review and editing, Y.-J.C., J.-H.L., J.-S.C., S.-J.A., Y.-M.H., J.-S.R. and K.-S.I.; investigation, K.-S.I.; synthesis, J.-H.L.; fabrication, Y.-J.C. and K.-S.I.; data collection of DC, LFN, pulse Y.-J.C. and K.-S.I.; All authors have read and agreed to the published version of the manuscript.

Funding: This research received no external funding.

Institutional Review Board Statement: Not applicable.

Informed Consent Statement: Not applicable.

Data Availability Statement: Not applicable.

Acknowledgments: This work was supported by the National Research Foundation of Korea Grant funded by the Korean Government (NRF-2018R1A6A1A03025761 and NRF-2019R111A1A01064011). This research was partially supported by NanoMaterial Technology Development Program through the NRF funded by the Ministry of Science, ICT and Future Planning (2009-0082580).

Conflicts of Interest: The authors declare no conflict of interest.

\section{References}

1. Wu, Y.-F.; Kapolnek, D.; Ibbetson, J.P.; Parikh, P.; Keller, B.P.; Mishra, U.K. Very-high power density AlGaN/GaN HEMTs. IEEE Electron Device Lett. 2001, 48, 586-590.

2. Ibbetson, J.P.; Fini, P.T.; Ness, K.D.; DenBaars, S.P.; Speck, J.S.; Mishra, U.K. Polarization effects, surface states, and the source of electrons in AlGaN/GaN heterostructure field effect transistors. Appl. Phys. Lett. 2007, 77, 250-252. [CrossRef]

3. Ambacher, O.; Smart, J.; Shealy, J.R.; Weimann, N.G.; Chu, K.; Murphy, M.; Schaff, W.J.; Eastman, L.F. Two-dimensional electron gases induced by spontaneous and piezoelectric polarization charges in $\mathrm{N}-$ and Ga-face AlGaN/GaN heterostructures. J. Appl. Phys. 1999, 85, 3222. [CrossRef]

4. Vetury, R.; Zhang, N.Q.; Keller, S.; Mishra, U.K. The impact of surface states on the DC and RF characteristics of AlGaN/GaN HFETs. IEEE Trans. Electron. Devices 2001, 48, 560-566. [CrossRef]

5. Luo, B.; Mehandru, R.J.; Kim, J.; Ren, F.; Gila, B.P.; Onstine, A.H.; Abernathy, C.R.; Pearton, S.J.; Fitch, R.; Gillespie, J.; et al. Comparison of Surface Passivation Films for Reduction of Current Collapse in AlGaN/GaN High Electron Mobility Transistors. J. Electrochem. Soc. 2002, 149, G613. [CrossRef]

6. Ma, J.; Lu, X.; Jiang, H.; Liu, C.; Lau, K.M. In situ growth of SiNx as gate dielectric and surface passivation for AlN/GaN heterostructures by metalorganic chemical vapor deposition. Appl. Phys. Exp. 2014, 7, 091002. [CrossRef]

7. Lee, J.-H.; Jeong, J.-H.; Lee, J.-H. Enhanced Electrical Characteristics of AlGaN-Based SBD with in Situ Deposited Silicon Carbon Nitride Cap Layer. IEEE Electron Device Lett. 2012, 33, 492-494. [CrossRef]

8. Vertiatchikh, A.V.; Eastman, L.F. Effect of the Surface and Barrier Defects on the AlGaN/GaN HEMT Low-Frequency Noise Performance. IEEE Electron Device Lett. 2003, 24, 535-537. [CrossRef]

9. Do, T.N.T.; Malmros, A.; Gamarra, P.; Lacam, C.; di Forte-Poisson, M.-A.; Tordjman, M.; Hörberg, M.; Aubry, R.; Rorsman, N.; Kuylenstierna, D. Effects of Surface Passivation and Deposition Methods on the 1/f Noise Performance of AllnN/AlN/GaN High Electron Mobility Transistors. IEEE Electron Device Lett. 2015, 36, 315-317. [CrossRef]

10. Hasan, M.R.; Motayed, A.; Fahad, M.S.; Rao, M.V. Fabrication and comparative study of DC and low frequency noise characterization of GaN/AlGaN based MOS-HEMT and HEMT. J. Vac. Sci. Technol. B 2017, 35, 052202. [CrossRef]

11. Rzin, M.; Guillet, B.; Méchin, L.; Gamarra, P.; Lacam, C.; Medjdoub, F.; Routoure, J.-M. Impact of the in situ SiN Thickness on Low-Frequency Noise in MOVPE InAlGaN/GaN HEMTs. IEEE Trans. Electron Devices 2019, 66, 5080-5083. [CrossRef]

12. Chroboczek, J.A.; Piantino, G. Low Noise Current Amplifier with Programmable Gain and Polarization for Use in Electrical Measurement of Semiconductor Circuits, such as Transistors, with the Circuit Being Low Noise and Having a Protection Circuit for the Input. France Patent No. 15075, 22 November 2000.

13. McWhorter, A.L. 1/f Noise and Germanium Surface Properties. In Semiconductor Surface Physics; University of Pennsylvania Press: Philadelphia, PA, USA, 1957; pp. 207-228. 
14. Choi, Y.J.; Lee, J.-H.; An, S.J.; Im, K.-S. Low-Frequency Noise Behavior of AlGaN/GaN HEMTs with Different Al Compositions. Crystals 2020, 10, 830. [CrossRef]

15. Ghibaudo, G.; Roux, O.; Nguyen-Duc, C.; Balestra, F.; Brini, J. Improved Analysis of Low Frequency Noise in Field-Effect MOS Transistors. Phys. Status Solidi A 1991, 124, 571-581. [CrossRef]

16. Ioannidis, E.G.; Dimitriadis, C.A.; Haendler, S.R.; Bianchi, A.; Jomaah, J.; Ghibaudo, G. Improved analysis and modeling of low-frequency noise in nanoscale MOSFETs. Solid-State Electron. 2012, 76, 54-59. [CrossRef]

17. Ghibaudo, G.; Boutchacha, T. Electrical noise and RTS fluctuations in advanced CMOS devices. Microelectron. Reliab. 2002, 42, 573-582. [CrossRef] 